\title{
Prevalence of Obesity, Overweight and Eating Disorders in a School-Based Population in Southern Brazil \\ Ricardo Rodrigo Rech1*and Ricardo Halpern
}

Federal University of Health Sciences of Porto Alegre, Brazil. University of Caxias do Sul, Brazil.

\begin{abstract}
The health of school-age children and adolescents has been the focus of much attention, since at this stage of life students experience biological, social, emotional and cognitive changes. The aim of this study was to determine the prevalence rates of obesity, overweight and symptoms of eating disorders (ED) among the sixth-grade students of the municipal schools in Caxias do Sul in 2011. A school-based, cross-sectional study evaluated 1230 students $(86.80 \%$ of the total). A self-report questionnaire and anthropometric measures of weight and height were used in the assessment. The prevalence rates of obesity, overweight and ED symptoms were $7.30 \%, 22.80 \%$ and $33.10 \%$, respectively. The students dissatisfied with their body image were four times more likely $(\mathrm{PR}=4.01 ; \mathrm{Cl} 95 \%=2.71-5.93)$ to have excess weight and nine times more likely $(P R=9.30 ; \mathrm{Cl} 95 \%=6.29-13.78)$ to have symptoms for ED. The prevalence rates of ED symptoms, obesity and overweight of the evaluated students are high and warrant the attention of the community as a whole.
\end{abstract}

Keywords: Obesity, Eating disorders, Body image, Cross-sectional studies.

\section{Introduction}

The health of school-age children and adolescents has been the focus of much attention, since at this stage of life students experience biological, social, emotional and cognitive changes [1]. This is a time when exposure to environment-related risk factors such as inadequate diet and sedentary behavior begins and may persist throughout adulthood [2]. Furthermore, these factors are associated with most chronic non-communicable diseases, such as cardiovascular disease, diabetes and cancer, which are the leading causes of adult death in Brazil $[2,3]$.

The nutritional status of children and adolescents has undergone a shift termed "nutrition transition", which corresponds to increases in the prevalence of obesity and overweight and a reduction in the prevalence of malnutrition [4]. In Brazil, the studies addressing these issues report different prevalence rates and varying associated factors (eating habits, sedentary behavior, level of physical activity, socioeconomic status) depending on the location where the research was conducted and the evaluation methodology applied [5-7]. Other factors that have been associated with overweight are dissatisfaction with the body image and bullying [7].

Depending on the evaluation instrument and the population under study, the prevalence of ED symptoms may vary. In six towns in the interior of Minas Gerais, Vilela et al. [8] found $13.30 \%$ of students with possible ED; in Finland[9], a study found $2.60 \%$ prevalence for anorexia nervosa, $0.40 \%$ for bulimia nervosa and $8.50 \%$ for subclinical eating disorders. As with nutritional status, dissatisfaction with the body image is seen as a factor strongly associated to ED [10].

Different prevalence rates were noted for the outcomes in question depending on the study location, a fact that highlights the importance of conducting prevalence studies in the various Brazilian regions by virtue of the cultural, climatic and geographical particularities of each location $[5-8,10]$. The overall objective of the present study was to determine the prevalence rates of obesity, overweight and ED symptoms among sixth-grade students of the municipal schools in Caxias do Sul, RS, and the possible associations of those outcomes with mother's schooling, economic classification, dissatisfaction with the body image, bullying and lifestyle (physical activity, sedentary behavior and diet).

\section{Methods}

The present study is a school-based, cross-sectional, epidemiologic study that represents the first phase of a larger project denominated "Obesity, body image dissatisfaction and symptoms of eating disorders in a student cohort in the Serra Gaucha".

A population of 4300 sixth-grade students was found (age range, 11-14 years). To determine sample size, a prevalence of $50 \%$ (as the outcomes showed different prevalence rates), a 95\% confidence interval (CI) and a $3 \%$ error were assumed; thus, it would be necessary to evaluate a minimum of 855 children. In order to secure greater control over the confounding factors, a design effect of 1.40 was calculated, which required the evaluation of 1197 students. The statistical software Epi-Info 6.0 was used to calculate the sample size.

The cluster sampling method was used, by which each school was regarded as a cluster. The randomized selection for the final sample included only the schools that had sixth grade classes. All the schools fulfilling this requirement were included in the selection and had the same chance of study participation according to the number of sixthgraders enrolled in the school on the selection date. All the students of the school who fulfilled the inclusion criteria were invited to participate in the study. Twenty-two schools were randomly selected to complete the minimum number of students to be evaluated (total $n=1417$ ).

The following inclusion criteria were established: age between 11-14 years, no disabilities or any complication preventing the practice of physical activity, informed consent signed by the students' parents or legal guardians, and voluntary participation.

*Corresponding author: Professor Ricardo Rodrigo Rech, Federal University of Health Sciences of Porto Alegre, Brazil, Tel: 55 -54 91620290; E-mail: ricardo.rech@gmail.com

Received July 10, 2013; Accepted December 06, 2013; Published December 11,2013

Citation: Rech RR, Halpern R (2013) Prevalence of Obesity, Overweight and Eating Disorders in a School-Based Population in Southern Brazil. J Biosafety Health Educ 1: 111. doi:10.4172/2332-0893.1000111

Copyright: $\odot 2013$ Rech RR, et al. This is an open-access article distributed under the terms of the Creative Commons Attribution License, which permits unrestricted use, distribution, and reproduction in any medium, provided the original author and source are credited. 


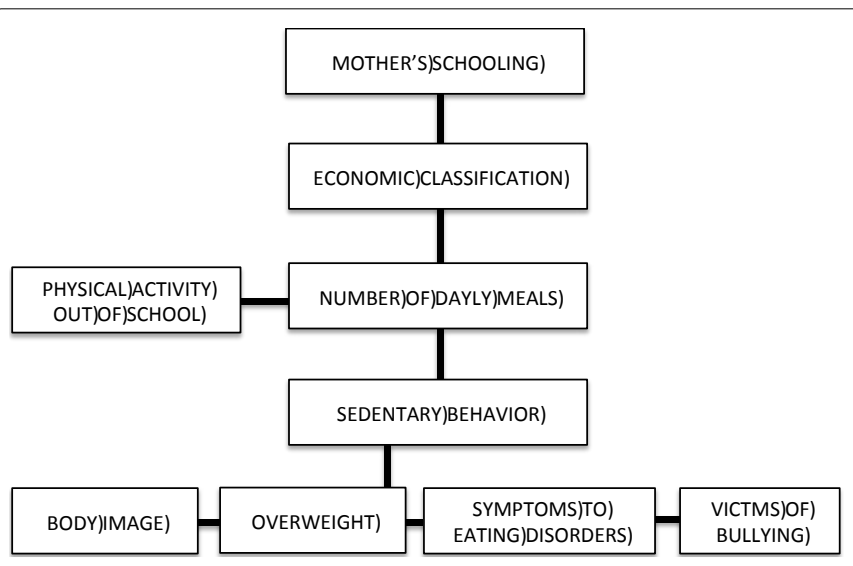

Figure 1: Theoretical framework adopted in the present study.

A self-report questionnaire was used in the assessment of the following variables: economic classification, gender, age, lifestyle habits, Eating Attitudes Test (EAT-26), body image dissatisfaction and bullying. To evaluate the students' eating habits, the number of daily meals was assessed, with the students marking which meals they usually had in a day (response choices: breakfast, morning snack, lunch, afternoon snack, dinner, supper; if others, specify). The students were also questioned as to physical activity out of school (yes or no) and sedentary behavior (number of hours per day involved in activities such as watching television, playing video games and using the computer).

The information concerning the economic classification was organized in accordance with that proposed by Barros and Victora [11], which takes into account 13 variables to constitute the National Wealth Score (Indicador Econômico Nacional, IEN). The students were classified into three categories: low, intermediate and high class.

The EAT-26, an instrument translated and validated for the Brazilian adolescent population by Bighetti [12], was used to screen for symptoms of ED. The EAT-26 evaluates the risks of developing behavior and attitudes typical of patients with anorexia nervosa. This instrument consists of 26 questions with six response choices for each. The established cut-off was 21 points or higher for EAT+ (presence of ED symptoms).

Dissatisfaction with the body image was investigated using the Body Shape Questionnaire (BSQ), which measures the extent of concerns with the body shape and self-depreciation motivated by physical appearance and feelings of being out of shape. The BSQ has been validated for adolescents in its Brazilian version by Conti, Cordás and Latorre [13] and comprises 34 questions with six possible responses.

To characterize victims of bullying, the Kidscape questionnaire was administered [14]. This questionnaire, in the adapted version for the present study, contains 14 questions that identify victims and aggressors. The definition of the outcome victim of bullying was based on the question that elicits the number of times the respondent was subjected to some form of intimidation; bullying is characterized if the fact occurred more than once in the previous month.

In addition to the self-report questionnaire, measurements of total body mass and height were taken. The measurement of total body mass was performed using a Plenna portable digital scale with accuracy of $0.1 \mathrm{~kg}$. Height was measured with a wall-mounted stadio meter and a set square. The nutritional status of the students was defined using the body mass index (BMI) cut-off points by gender and age developed by Conde and Monteiro [15]. The children were classified as underweight, healthy weight, overweight and obese. For the bivariate and multivariate analyses, the underweight and healthy weight children were grouped together to compose the "no overweight" variable; the same was done with the overweight and obese children to establish the variable "overweight".

The entire assessment team (15 evaluators) was trained so the evaluations could be standardized; a handbook was prepared and distributed among them for the assessments. A pilot study was undertaken with 15 children of a school that was out of the final study sample, in which the logistic aspects of the project were ascertained, such as questionnaire language verification and standardization of the anthropometric measurements performed by the evaluators. The assessments were conducted in March and April 2011.

Following the collection of the data, these were entered twice in a database formatted in EPIDATA version 3.1. After verifying the consistency of the data, these were exported to the IBM-SPSS software version $19^{\circ}$ for analysis. Initially, a descriptive analysis was performed, followed by bivariate (Pearson's chi square test) and multivariate analysis (logistic regression) between the independent variables and outcomes. A significance level of $20 \%$ was adopted as a statistical criterion to maintain a variable in the regression model, and also based on the plausibility of the association. The prevalence ratio (PR) and $95 \%$ confidence interval (CI) were presented for all associations. The theoretical framework adopted in the present study is outlined in Figure 1. The mother's schooling variable is on the first hierarchical level, followed by socio-economic status on the second level. The number of daily meals was included on the third level and sedentary habits on the fourth.

Regarding the ethical proceedings, informed consent forms were given to all the children in the study sample. In addition to parental consent, the students who composed the sample agreed to participate in the study on a voluntary basis. The research project was approved by the UFCSPA Research Ethics Committee with Opinion 1312/11 and registry no. $741 / 11$.

\section{Results}

In total, 1417 children were randomly selected for the study (ages between 11-14 years), and 1230 composed the final sample ( $86.80 \%$ of the total). One child was excluded for not agreeing with the inclusion criteria, 16 refused to participate, and 170 failed to return a signed informed consent. The sample was equally distributed between genders with 606 girls and 624 (50.70\%) boys. The assessment comprised 562 $(45.70 \%)$ students aged 12 years; $452(36.70 \%)$ aged 11 years; 159 $(12.90 \%)$ aged 13 , and $57(4.60 \%)$ students 14 years. The mean age of the evaluated students was 11.85 years $(\mathrm{SD}=0.82)$.

In the overall sample, the means for the anthropometric variables weight, height and $\mathrm{BMI}$ were, respectively, $44.89 \mathrm{~kg}(\mathrm{SD}=12.72), 1.50$ $\mathrm{m}(\mathrm{SD}=0.08)$ and $19.58 \mathrm{~kg} / \mathrm{m}^{2}(\mathrm{SD}=3.75)$. The means for number of daily meals and number of hours sitting by the television, video game and computer were $3.72(\mathrm{SD}=1.24)$ and $2.21(\mathrm{SD}=1.16)$, respectively. Eighteen percent of the students were found to be dissatisfied with their body image ( $24.80 \%$ girls and $11.50 \%$ boys). The other characteristics of the study participants are shown in Table 1.

The prevalence of obesity, overweight and ED symptoms were $7.30 \%, 22.80 \%$ and $33.10 \%$. Eleven $(0.90 \%)$ underweight students were also found. 
Citation: Rech RR, Halpern R (2013) Prevalence of Obesity, Overweight and Eating Disorders in a School-Based Population in Southern Brazil. J Biosafety Health Educ 1: 111. doi:10.4172/2332-0893.1000111

Page 3 of 6

\begin{tabular}{|l|c|c|}
\hline & $\mathbf{n}$ & $\%$ \\
\hline Mother's schooling & & 62,0 \\
\hline Elementary education & 701 & 38,0 \\
\hline High school or higher & 430 & \\
\hline & & 4,8 \\
\hline Economic classification & 52 & 48,7 \\
\hline Low & 528 & 46,5 \\
\hline Intermediate & 505 & \\
\hline High & & 39,2 \\
\hline & & 60,8 \\
\hline Number of daily meals & 481 & \\
\hline Until 3 & 745 & \\
\hline 4 or mor & & 64,6 \\
\hline & & 35,4 \\
\hline Sedentary behavior (TV, & & \\
\hline videogame, computer) & & \\
\hline Until 3 per day & 485 & 47,8 \\
\hline Mor of 3 per day & & \\
\hline & & \\
\hline Physical activity out of school & & \\
\hline Yes & & \\
\hline No & & \\
\hline & & \\
\hline Victims of bullying & & \\
\hline No & & \\
\hline Yes & & \\
\hline & & \\
\hline & & \\
\hline
\end{tabular}

TV= television

Table 1: Characteristics of the study participants (Caxias do Sul, $2011-n=1230$ ).

For the bivariate and multivariate analyses, the theoretical framework variables were grouped into dichotomous variables. Tables 2 and 3 display the results of the bivariate and multivariate analyses.

The variables mother's schooling, economic classification, physical activity out of school, sedentary habits, bullying, gender and age showed no statistically significant association with overweight $(p>0.05)$ in the bivariate and multivariate analyses.

The number of daily meals equal to or greater than, four was found to be a protective factor for weight excess. The students who reported that eating habit were $42 \%$ less likely ( $P R=0.58 ; C I=0.43-0.78)$ to be overweight compared to those who ingested up to three meals per day.

The students who felt dissatisfied with their body image were four times more likely $(\mathrm{PR}=4.01 ; \mathrm{CI}=2.71-5.93)$ to be overweight compared with students satisfied with their body image (Table 2).

The variables mother's schooling, economic classification, sedentary habits and age showed no statistically significant association with ED symptoms $(p>0.05)$.

The students who had excess weight were $56 \%$ more likely to have symptoms of ED compared with those who had no overweight/obesity $(\mathrm{PR}=1.56 ; \mathrm{CI}=1.12-2.16)$.

The number of daily meals was significantly associated with the symptoms of ED only in the bivariate analysis, as the students who reported four or more meals per day were $25 \%$ less likely $(\mathrm{PR}=0.75$; $\mathrm{CI}=0.59-0.96)$ to have ED symptoms relative to the students who had up to three meals per day.

The level of physical activity was associated with ED symptoms. The students who reported no physical activity out of school were $46 \%$ less

likely ( $\mathrm{PR}=0.54$; $\mathrm{CI}=0.40-0.74)$ to show $\mathrm{ED}$ symptoms than those who exercised out of school hours. Among the students who reported outof-school physical activity, 50.40\% responded "I think about burning up calories when I exercise" (question 12 of the EAT-26).

The students who declared body image dissatisfaction were nine times more likely ( $\mathrm{PR}=9.30 ; \mathrm{CI}=6.29-13.78)$ to have symptoms of $\mathrm{ED}$ compared with the satisfied students. Being a victim of bullying was associated with ED symptoms only in the bivariate analysis, where the victims were $78 \%$ more likely ( $\mathrm{PR}=1.78$; $\mathrm{CI}=1.23-2.58)$ to have those symptoms than non-victims of bullying. In the bivariate analysis, the students who were not satisfied with their body image were more than twice as likely to be victims of bullying ( $\mathrm{PR}=2.46$; $\mathrm{CI}=1.64-3.69)$.

The boys were $40 \%$ less likely ( $\mathrm{PR}=0.60 ; \mathrm{CI}=0.45-0.82$ ) to show $\mathrm{ED}$ symptoms than the girls (Table 3 ).

\begin{tabular}{|c|c|c|c|c|}
\hline & \begin{tabular}{|c|} 
Crude PR \\
(bivariate)
\end{tabular} & $\mathrm{Cl}$ de $95 \%$ & $\begin{array}{l}\text { Adjusted PR } \\
\text { (multivariate) }\end{array}$ & $\mathrm{Cl}$ de $95 \%$ \\
\hline \multicolumn{5}{|l|}{$\begin{array}{l}\text { Mother's schooling (10 } \\
\text { level) }\end{array}$} \\
\hline Elementary education & 1,00 & & 1,00 & \\
\hline High school or higher & 1,11 & $0,86-1,45$ & 1,25 & $0,91-1,71$ \\
\hline \multicolumn{5}{|l|}{$\begin{array}{l}\text { Economic } \\
\text { classification }\left(2^{\circ} \text { level }\right)\end{array}$} \\
\hline Low and intermadiate & 1,00 & & 1,00 & \\
\hline High & 1,18 & $0,91-1,54$ & 1,09 & $0,80-1,49$ \\
\hline \multicolumn{5}{|l|}{$\begin{array}{l}\text { Number of daily meals } \\
\left(3^{\circ} \text { level }\right)\end{array}$} \\
\hline Until 3 & 1,00 & & 1,00 & \\
\hline 4 or mor & $0,59^{*}$ & $0,46-0,76$ & $0,58^{*}$ & $0,43-0,78$ \\
\hline \multicolumn{5}{|l|}{$\begin{array}{l}\text { Physical activity out of } \\
\text { school }\end{array}$} \\
\hline Yes & 1,00 & & 1,00 & \\
\hline No & 1,07 & $0,83-1,38$ & 1,001 & $0,74-1,36$ \\
\hline \multicolumn{5}{|l|}{$\begin{array}{l}\text { Sedentary behavior }\left(4^{\circ}\right. \\
\text { level) }\end{array}$} \\
\hline Until 3 per day & 1,00 & & 1,00 & \\
\hline Mor of 3 per day & 0,93 & $0,71-1,20$ & 1,03 & $0,76-1,40$ \\
\hline \multicolumn{5}{|l|}{ Body Image ( $5^{\circ}$ level) } \\
\hline Satisfied & 1,00 & & 1,00 & \\
\hline Dissatisfied & $5,67^{*}$ & $4,15-7,75$ & $4,01^{*}$ & $2,71-5,93$ \\
\hline \multicolumn{5}{|l|}{ Victims of bullying } \\
\hline No & 1,00 & & 1,00 & \\
\hline Yes & 1,18 & $0,79-1,76$ & 1,07 & $0,65-1,75$ \\
\hline \multicolumn{5}{|l|}{ Sex ( $6^{\circ}$ level) } \\
\hline Female & 1,00 & & 1,00 & \\
\hline Male & 0,87 & $0,68-1,12$ & 1,31 & $0,96-1,78$ \\
\hline \multicolumn{5}{|l|}{ Age } \\
\hline 11 years & 1,00 & & 1,00 & \\
\hline 12,13 and 14 years & 0,90 & $0,70-1,16$ & 0,66 & $0,44-1,002$ \\
\hline
\end{tabular}

$\mathrm{Cl}=$ Confidence Interval; PR = Prevalence Ratio; ${ }^{*}=\mathrm{p}<0,05$;

Table 2: Bivariate and multivariate analyzes between overweight and dependents variables. 


\begin{tabular}{|c|c|c|c|c|}
\hline & $\begin{array}{l}\text { Crude PR } \\
\text { (bivariate) }\end{array}$ & $\mathrm{Cl}$ de $95 \%$ & $\begin{array}{l}\text { Adjusted PR } \\
\text { (multivariate) }\end{array}$ & $\mathrm{Cl}$ de $95 \%$ \\
\hline \multicolumn{5}{|c|}{$\begin{array}{l}\text { Mother's schooling }\left(1^{\circ}\right. \\
\text { level) }\end{array}$} \\
\hline Elementary education & 1,00 & & 1,00 & \\
\hline High school or higher & 0,80 & $0,62-1,04$ & 0,86 & $0,62-1,18$ \\
\hline \multicolumn{5}{|c|}{$\begin{array}{l}\text { Economic } \\
\text { classification }\left(2^{\circ} \text { level }\right)\end{array}$} \\
\hline Low and intermadiate & 1,00 & & 1,00 & \\
\hline High & 0,94 & $0,73-1,21$ & 0,94 & $0,69-1,28$ \\
\hline \multicolumn{5}{|c|}{$\begin{array}{l}\text { Number of daily meals } \\
\left(3^{\circ} \text { level }\right)\end{array}$} \\
\hline Until 3 & 1,00 & & 1,00 & \\
\hline 4 or mor & $0,75^{*}$ & $0,59-0,96$ & 0,99 & $0,73-1,33$ \\
\hline \multicolumn{5}{|c|}{$\begin{array}{l}\text { Physical activity out of } \\
\text { school }\end{array}$} \\
\hline Yes & 1,00 & & 1,00 & \\
\hline No & $0,72^{*}$ & $0,57-0,92$ & $0,54^{*}$ & $0,40-0,74$ \\
\hline \multicolumn{5}{|c|}{$\begin{array}{l}\text { Sedentary behavior }\left(4^{\circ}\right. \\
\text { level) }\end{array}$} \\
\hline Until 3 per day & 1,00 & & 1,00 & \\
\hline Mor of 3 per day & 0,81 & $0,63-1,04$ & 0,91 & $0,67-1,24$ \\
\hline \multicolumn{5}{|l|}{ Overweight $\left(5^{\circ}\right.$ level $)$} \\
\hline No Overweight & 1,00 & & 1,00 & \\
\hline Overweight & 2,52 & $1,95-3,26$ & $1,56^{*}$ & $1,12-2,16$ \\
\hline \multicolumn{5}{|l|}{ Body Image } \\
\hline Satisfied & 1,00 & & 1,00 & \\
\hline Dissatisfied & $11,31^{*}$ & $8,00-16,01$ & $9,30^{*}$ & $\begin{array}{l}6,29- \\
13,78\end{array}$ \\
\hline \multicolumn{5}{|l|}{ Victims of bullying } \\
\hline No & 1,00 & & 1,00 & \\
\hline Yes & $1,78^{*}$ & $1,23-2,58$ & 1,26 & $0,77-2,07$ \\
\hline \multicolumn{5}{|l|}{ Sex (6 $6^{\circ}$ level) } \\
\hline Female & 1,00 & & 1,00 & \\
\hline Male & $0,56^{*}$ & $0,44-0,71$ & $0,60^{*}$ & $0,45-0,82$ \\
\hline \multicolumn{5}{|l|}{ Age } \\
\hline 11 years & 1,00 & & 1,00 & \\
\hline 12,13 and 14 years & 1,09 & $0,80-1,49$ & 0,96 & $0,65-1,42$ \\
\hline
\end{tabular}

$\mathrm{Cl}=$ Confidence Interval; $\mathrm{PR}=$ Prevalence Ratio; ${ }^{*}=\mathrm{p}<0,05$;

Table 3: Bivariate and multivariate analyzes between symptoms for eating disorders and independents variables.

\section{Discussion}

The present study found $30.10 \%$ of overweight students, a higher rate compared with the study carried out in Denmark [7], in which the children and adolescents had $1.10 \%$ obesity and $8.60 \%$ overweight. Comparing the results of the current study with other Brazilian studies, they are higher than those found in the cities of Florianópolis, which showed $21.90 \%$ of overweight students, Maceió [16], with $13.80 \%$ of overweight students, and Sorocaba [17], where $22.10 \%$ of the students were overweight or obese.

The present study also yielded higher values than those found in previous Caxias do Sul studies. In 2007[5], 27.90\% prevalence

was found for overweight, and in 2010 [18], the prevalence rates for overweight and obesity were $15.10 \%$ (half the prevalence noted in the present study). These high prevalence rates can be explained in part by the diet that the Caxias do Sul pre-schoolers have been receiving, especially at home. The children have been consuming fewer adequate foods and more of those with added sugar and chocolate-a behavior that can be regarded as a risk for overweight and obesity, since these habits will be the major determinants of their food intake later in life $[18,19]$.

Regarding ED symptoms, the students evaluated in the current study showed superior values to those found in a study conducted by Vilela et al.[8] (2004) and in public and private schools in the region of Castilla and León in Spain, where a prevalence of $7.80 \%$ was reported [20].

The group of students dissatisfied with their body image was four times more likely to be overweight $(\mathrm{PR}=4.01)$ and nine times more likely to have symptoms of $\mathrm{ED}(\mathrm{PR}=9.30)$ relative to the satisfied students. Alves et al.[21], when evaluating 1148 girls in Florianópolis, also found strong associations between symptoms of ED and body image dissatisfaction $(\mathrm{OR}=14.39)$, and between excess weight and dissatisfaction with body image $(\mathrm{OR}=2.07)$. Other studies developed in Minas Gerais ${ }^{8}$ and in several regions of China [22], also showed associations between overweight, ED symptoms and body image dissatisfaction. Eating disorders are characterized by patterns of disordered eating behavior, pathological body weight control and body image distortions [23]. Obese children feel rejected, unhappy with their bodies; they suffer with this situation and would like to change because they are pressured by their social milieu [24].

Another result that could be related to those discussed above: the overweight students were $56 \%$ more likely to have symptoms of ED compared with those who were at a healthy weight/underweight $(\mathrm{PR}=1.56)$. These are similar results to those found in the cities of São Paulo [25] and Florianópolis [21] as well as in the study conducted in Spain [20], where the children and adolescents with overweight or obesity showed greater likelihood of ED symptoms.

Another trend noted in the present study was the greater prevalence of symptoms of ED in girls, as the boys were $40 \%$ less likely ( $P R=0.60)$ to have ED symptoms compared with the girls. Perhaps this trend is related to body image, since girls typically exhibit the highest prevalence rates of dissatisfaction and seek methods to alter their body shape, in order to emulate the standards of beauty imposed by society and disseminated by the media [26].

The level of physical activity was associated with ED symptoms. The students who reported no out-of-school physical activity were $46 \%$ less likely ( $\mathrm{PR}=0.54)$ to have $\mathrm{ED}$ symptoms. Cross-checking the variable physical activity with the EAT-26 question inquiring whether the child thought about burning calories when he/she exercised, it is possible to note that most children who responded always, very often and sometimes were those who had out-of-school activities, and perhaps this is a compensatory practice for weight control. Exercising with the purpose of losing weight and burning up calories is typical of individuals with ED symptoms [27], since regular and systematic exercise is one of the ways by which body weight control can be achieved [28].

The number of daily meals equal to, or greater than, four was a protective factor for symptoms of $\mathrm{ED}(\mathrm{PR}=0.75$; $\mathrm{CI}=0.59-0.96)$ and for overweight $(\mathrm{PR}=0.58 ; \mathrm{CI}=0.43-0.78)$. A study conducted in Florianopolis with 2826 students also showed a negative correlation between number of daily meals and obesity/overweight [3], as did 
another study conducted in Caxias do Sul [5], where eating four meals or more in a day was found to be a protective factor for overweight. Dividing the amount of daily food in a greater number of meals per day is a nutritional recommendation that can assist in weight control [29]; epidemiologic studies on the theme have been showing this inverse relationship between number of meals and overweight $[3,5]$.

The present study found $10.20 \%$ of victims of bullying. Different results were obtained in a study involving more than 60,000 students of public and private schools in the 26 Brazilian State capitals and the Federal District [30], which found 5.40\% of bullying victims. Being a victim of bullying was not associated with overweight; however, in the bivariate analysis, the victims of bullying were $78 \%$ more likely $(\mathrm{PR}=1.78)$ to show $\mathrm{ED}$ symptoms than those who were not bullying victims. Brixval et al.[7], (in Denmark) found an association between bullying and overweight, and posited that body image can account for the association between overweight/obesity and vulnerability to bullying. Given that dissatisfaction with body image and symptoms of ED were strongly associated, this association between being a victim of bullying and ED symptoms observed in the present study could be explained by the relationship between victimization and discontent with body image, since dissatisfied students were more than twice as likely to be the targets of bullying $(\mathrm{PR}=2.46)$. Obese children, as a consequence of their body image, are rated as less capable and more indolent; due to this stigma, they are eventually left out of school environment situations [24].

The variables physical activity out of school and sedentary habits were not significantly associated with overweight, as found in the Recife [6] and Sorocaba [17] studies. However, these results counter the findings of another study conducted in Caxias do Sul [5]. It seems that the associations between overweight, physical activity and sedentary habits have not yet been well established in epidemiologic studiespossibly because of the use of indirect measures (such as questionnaires) [6] and not direct measures of health-related physical fitness (such as running track testing) [5].

The variables mother's schooling and socioeconomic status showed no statistically significant association with ED symptoms or with overweight. Other studies $[3,16]$ found this association between better living conditions and overweight, and it may be that obesity and overweight issues are reaching the more underprivileged populations as well [5].

One limitation of the present study was the memory bias that may have occurred in the questions pertaining to eating habits and sedentary behavior. Also, reverse causality may have occurred due to the cross-sectional design of the study.

Because a representative sample of the target population was studied and the number of losses was low, the data of the present study can be extrapolated for the target population within the same age group. Considering the study limitations, it can be said that the prevalence rates of ED symptoms, obesity and overweight of the evaluated students are high.

Body image dissatisfaction was found to be strongly associated with overweight and symptoms of ED. Overweight was also associated with the number of daily meals. Symptoms of ED were associated with overweight, number of daily meals, physical activity, victims of bullying and the female gender.

The results of the present study serve as a warning sign to the study population and the community as a whole. Health promotion programs addressing these topics can be advanced by the town's school community. Further analyses of these students (by the longitudinal study) will more clearly establish the cause-and-effect relationships between the associated variables.

\section{Contributions}

Rech RR participated in the making of the project, field work, data analysis, drafting and approval of the final version of the manuscript. Halpern R participated in the making of the project, field work, data analysis, drafting and approval of the final version of the manuscript.

\section{References}

1. Legnani E, Legnani RF, Lopes AS, Campos W, Krinski K, et al. (2009) Risk behaviors related to health in adolescents from the tri-border region. RBAFS14:28-37.

2. Malta DC, Sardinha LM, Mendes I, Barreto SM, Giatti L, et al. (2010) Prevalence of risk health behavior among adolescents: results from the 2009 National Adolescent School-based Health Survey (PeNSE). Cien Saude Colet 15 Suppl 2: 3009-3019.

3. Bernardo Cde O, Vasconcelos Fde A (2012) Association of parents' nutritional status, and sociodemographic and dietary factors with overweight/obesity in schoolchildren 7 to 14 years old. Cad Saude Publica 28: 291-304.

4. Wang Y, Monteiro C, Popkin BM (2002) Trends of obesity and underweight in older children and adolescents in the United States, Brazil, China, and Russia. Am J Clin Nutr 75: 971-977

5. Costanzi CB, Halpern R, Rech RR, Bergmann ML, Alli LR, et al. (2009) Associated factors in high blood pressure among schoolchildren in a middle size city, southern Brazil. J Pediatr (Rio J) 85: 335-340

6. Alves JG, Siqueira PP, Figueiroa JN (2009) Overweight and physical inactivity in children living in favelas in the metropolitan region of Recife, Brazil. J Pediat (Rio J) 85: 67-71.

7. Brixval CS, Rayce SL, Rasmussen M, Holstein BE, Due P (2012) Overweight body image and bullying--an epidemiological study of 11- to 15 -years olds. Eur J Public Health 22: 126-130.

8. Vilela JE, Lamounier JA, Dellaretti Filho MA, Barros Neto JR, Horta GM (2004) [Eating disorders in school children]. J Pediatr (Rio J) 80: 49-54

9. Isomaa R, Isomaa AL, Marttunen M, Kaltiala-Heino R, Björkqvist K (2009) The prevalence, incidence and development of eating disorders in Finnish adolescents: a two-step 3-year follow-up study. Eur Eat Disord Rev 17: 199207

10. Yager Z, O'Dea J (2009) Body image, dieting and disordered eating and activity practices among teacher trainees: implications for school-based health education and obesity prevention programs. Health Educ Res 24: 472-482.

11. Barros AJ, Victora CG (2005) A nationwide wealth score based on the 2000 Brazilian demographic census. Rev Saude Publica 39: 523-529.

12. Bighetti $F$ (2003) Tradução e validação do Eating Attitudes Test (EAT-26) em adolescentes do sexo feminino na cidade de Ribeirão Preto - SP [tese de mestrado]. Ribeirão Preto (SP): EERP/USP.

13. Conti MA, Cordás TA, Latorre MR (2009) A study of the validity and reliability of the Brazilian version of the Body Shape Questionnaire (BSQ) among adolescents. Rev Bras Saude Mater Infantil 9:331-8.

14. Kidscape [homepage on the Internet]. Kidscape: preventing bullying, protectin children [cited 2011 Apr 4]. Available from: http://www.kidscape.org.uk

15. Conde WL, Monteiro CA (2006) Body mass index cutoff points for evaluation of nutritional status in Brazilian children and adolescents. J Pediatr (Rio J) 82 266-272.

16. Mendonça MR, Silva MA, Rivera IR, Moura AA (2010) Prevalence of overweight and obesity in children and adolescents from the city of Maceió (AL). Rev Assoc Med Bras 56: 192-196.

17. Mazaro IA, Zanolli Mde L, Antonio MÂ, Morcillo AM, Zambon MP (2011) Obesity and cardiovascular risk factors in school children from Sorocaba, SP. Rev Assoc Med Bras 57: 674-680.

18. Hoffmann M, Silva AC, Siviero J (2010) Prevalence of hypertension and interrelations with overweight, obesity, food intake and physical activity in students of municipal schools of Caxias do Sul. Pediatria (São Paulo) 32:163-72. 
Citation: Rech RR, Halpern R (2013) Prevalence of Obesity, Overweight and Eating Disorders in a School-Based Population in Southern Brazil. J Biosafety Health Educ 1: 111. doi:10.4172/2332-0893.1000111

19. Bernardi JR, Cezaro CD, Fisberg RM, Fisberg M, Vitolo MR (2010) Estimation of energy and macronutrient intake at home and in the kindergarten programs in preschool children. J Pediatr (Rio J) 86: 59-64.

20. Vega Alonso AT, Rasillo Rodríguez MA, Lozano Alonso JE, Rodríguez Carretero G, Martín MF (2005) Eating disorders. Prevalence and risk profile among secondary school students. Soc Psychiatry Psychiatr Epidemiol 40: 980-987.

21. Alves E, Vasconcelos Fde A, Calvo MC, Neves Jd (2008) [Prevalence of symptoms of anorexia nervosa and dissatisfaction with body image among female adolescents in Florianópolis, Santa Catarina State, Brazil]. Cad Saude Publica 24: 503-512.

22. Chen $H$, Jackson $T$ (2008) Prevalence and sociodemographic correlates of eating disorder endorsements among adolescents and young adults from China. Eur Eat Disord Rev 16: 375-385.

23. Saikali CJ, Soubhia CS, Scalfaro BM, Cordas TA (2004) Imagem corporal nos transtornos alimentares. Rev Psiquiatr Clin 31:164-166.

24. Feldmann LR, Mattos AP, Halpern R, Rech RR, Bonne CC et al. (2009) Implicações psicossociais da obesidade infantil em escolares de 7 a 12 anos de uma cidade serrana do sul do Brasil. RBONE 3:255-233.
25. Dunker KL, Fernandes CP, Carreira Filho D (2009) Socioeconomic influence on eating disorders risk behaviors in adolescents. J Bras Psiquiatr;58:156-161.

26. Del Duca GF, Garcia LM, Sousa TF, Oliveira ES, Nahas MV (2010) Body weight dissatisfaction and associated factors among adolescents. Rev Paul Pediatr 28:340-346.

27. Cancela Carral JM, Ayán Pérez C (2011) Prevalence and relationship between physical activity and abnormal eating attitudes in Spanish women university students in Health and Education Sciences. Rev Esp Salud Publica 85: 499505.

28. Alves JG, Galé CR, Souza E, Batty GD (2008) Effect of physical exercise on bodyweight in overweight children: a randomized controlled trial in a Brazilian slum. Cad Saude Publica 24 Suppl 2: S353-359.

29. Toassa EC, Leal GVS, Wen CL, Philippi ST (2010) Recreational activities in the nutritional guidance of adolescents in the Young Doctor Project. Nutrire: Rev Soc Bras Alim Nutr 35: 17-27.

30. Malta DC, Silva MA, Mello FC, Monteiro RA, Sardinha LM, et al. (2010) [Bullying in Brazilian schools: results from the National School-based Health Survey (PeNSE), Cien Saude Colet 15 Suppl 2: 3065-3076. 